MSC 91A10, 91A50

\title{
Opinion dynamics game in a social network with two influence nodes*
}

\author{
A. A. Sedakov ${ }^{1,2,3}$, M. Zhen ${ }^{1}$ \\ 1 St. Petersburg State University, 7-9, Universitetskaya nab., St. Petersburg, \\ 199034, Russian Federation \\ 2 School of Mathematics and Statistics, Qingdao University, 308, Ningxia Road, Qingdao, \\ 266071, People's Republic of China \\ 3 Institute of Applied Mathematics of Shandong, 308, Ningxia Road, Qingdao, \\ 266071, People's Republic of China
}

For citation: Sedakov A.A., Zhen M. Opinion dynamics game in a social network with two influence nodes. Vestnik of Saint Petersburg University. Applied Mathematics. Computer Science. Control Processes, 2019, vol. 15, iss. 1, pp. 118-125. https://doi.org/10.21638/11702/ spbu10.2019.109

\begin{abstract}
We consider an opinion dynamics game in a social network with two influence nodes. Pursuing certain goals, the influence nodes affect other members of the network by the selection of their levels of influence. Considering this model as a 2-person non-cooperative dynamic game and choosing Nash equilibrium as its solution, we find the equilibrium levels of influence for both influence nodes at any game stage. We also perform the numerical simulation for both low and high levels of players' influence on agents.
\end{abstract}

Keywords: social network, influence, opinion dynamics, equilibrium.

1. Introduction. In social networks, individuals form and revise their opinions depending on some influential opinions in the complex interpersonal environment. DeGroot [1] first introduced the mathematical theory of opinion dynamics by drawing on the algebra of a Markov chain. In his work, he focused on finding a consensus assuming that any agent considers his stage opinion to be a linear combination of agents' opinions at the previous stage. Friedkin and Johnsen $[2,3]$ enriched the social influence network theory by describing a social influence process affected by both endogenous opinions and exogenous conditions. Some recent results based on the DeGroot and Friedkin-Johnsen models can be found in $[4,5]$. Many works have extended the models of opinion dynamics with applications in social and political sciences, economics, engineering and computer sciences [6-8]. In [9], the authors develop a bounded confidence framework for a FriedkinJohnsen model presenting a series of simulations. The concept of the stubbornness of agents regarding their initial opinions was considered in [10], while [11] studied the wisdom groups under the DeGroot opinion dynamics. The problem of reaching a consensus was also studied in $[12,13]$ for a specific structure of a network with three groups of agents influenced by two nodes.

The models in the aforementioned papers were not examined from game-theoretic perspective. Different game-theoretic approaches can be applied to analyze opinion dynamics. For example, studies [14, 15] develop a controlled DeGroot model of opinion dynamics; [16] considers a Hegselmann-Krause model in a well-designed potential game. The present paper considers a model of influence in the opinion formation process as a noncooperative discrete-time linear-quadratic game, in which players' objectives are close to

* This work was supported by the Russian Foundation for Basic Research (grant N 17-51-53030) and Shandong Province "Double-Hundred Talent Plan" (grant N WST2017009).

(C) Санкт-Петербургский государственный университет, 2019 
those in $[17,18]$. In the model, players choosing their influence levels (control variables) wish to make agents' opinions in a network close to "desired" opinions minimizing the associated costs. Models of opinion formation can also use evolutionary game theory approaches, however they deal with different techniques which are not relevant to the model presented in this paper.

The structure of the paper is the following. In section 2, we describe an opinion dynamics model in a social network as a two-person non-cooperative discrete-time linearquadratic game. As a solution to this game, we consider a feedback Nash equilibrium which is presented in section 3 where we also provide a system of recurrence relations to find the equilibrium. A numerical simulation illustrating the results is presented in section 4 . For simulation, we consider a social network with the agents of three types (agents influenced by both players, agents influenced only by one player, and agents not influenced by players directly) and two scenarios of players' influence (low and high levels of influence on agents).

2. The model. We consider an opinion dynamics discrete-time model in a social network over a finite set of stages $\mathcal{T}=\{0,1, \ldots, T\}$. The social network is represented by a pair $(V, E)$ where $V$ is a finite set of nodes and $E$ is a set of edges between the nodes reflecting their communication structure. We suppose that the set of nodes can be decomposed as $V=A \cup N, A \cap N=\varnothing$. We call a node from $A$ by an agent and a node from $N$ by an influence node or a player. Therefore, the set $A$ is an agent set and $N$ is a player set in the network. Further, we suppose that each agent $i \in A$ in the network has its own opinion on a "subject" which can be changed over time. We suppose that agents' opinions are numerical values. Denote by $x_{i 0} \in[0,1]$ the initial opinion of agent $i$ whereas $x_{i}(t) \in[0,1]$ represents his opinion at stage $t=1, \ldots, T$. Let $x(t)=\left(x_{i}(t), i \in A\right)^{\prime}$ and $x_{0}=\left(x_{i 0}, i \in A\right)^{\prime}$ denote opinion profiles of agents at stage $t$ and at the initial stage, respectively.

Players (influence nodes) can influence agents' opinions. For simplicity, we assume that there are two influence nodes in the network, i. e. $N=\{1,2\}$. Denote by $u_{k}(t) \in[0,1]$ the action of player $k \in N$ on network agents (her influence level) selected at stage $t=$ $0, \ldots, T-1$. Each agent can evaluate his opinion at any stage aggregating the opinions of other agents in the network as well as the influence efforts of players. The opinion dynamics for agent $i \in A$ is governed by the equation

$$
x_{i}(t+1)=\sum_{j \in A} w_{i j} x_{j}(t)+b_{i 1} u_{1}(t)+b_{i 2} u_{2}(t), \quad t=0, \ldots, T-1,
$$

with $x_{i}(0)=x_{i 0}$. Here, $w_{i j} \in[0,1]$ is a level of trust of agent $i \in A$ to the opinion of agent $j \in A$ and $b_{i k} \in[0,1]$ is a level of trust of agent $i \in A$ to the opinion of player $k \in N$. It is not necessarily that $w_{i j}=w_{j i}$. Additionally, we assume that $\sum_{j \in A} w_{i j}+\sum_{k \in N} b_{i k}=1$ for any agent $i \in A$. The opinions of players are considered to remain constant over time and hence are not included into the model. Let $W=\left\{w_{i j}\right\}_{i, j \in A}, b_{k}=\left(b_{k i}, i \in A\right)^{\prime}, k \in N$. Then the opinion dynamics of agents in the network is given by

$$
x(t+1)=W x(t)+b_{1} u_{1}(t)+b_{2} u_{2}(t), \quad t=0, \ldots, T-1, \quad x(0)=x_{0} .
$$

We also decompose the set of edges $E$ into two disjoint sets $E_{A}$ and $E_{N}$, i. e. $E=E_{A} \cup E_{N}$ in which $E_{A}$ describes all connections between agents and $E_{N}$ describes all connections between pairs "player-agent". In the following, we identify the set $E$ with matrix $W$ and vectors $b_{1}$ and $b_{2}: w_{i j}>0$ if and only if $(j, i) \in E_{A} ; b_{i k}>0$ if and only if $(k, i) \in E_{N}$.

A player $k \in N$ selecting an admissible profile of actions in $T$ stages (or a strategy) $u_{k}=\left(u_{k}(0), \ldots, u_{k}(T-1)\right) \in[0,1]^{T}$ and taking into account opinion dynamics $x(t+1)=$ $W x(t)+b_{1} u_{1}(t)+b_{2} u_{2}(t)$, aims at minimizing his payoff function, which is given by 


$$
J_{k}\left(u_{1}, u_{2}\right)=\sum_{t=0}^{T-1}\left(\sum_{j \in A}\left(x_{j}(t)-\hat{x}_{k}\right)^{2}+c_{k} u_{k}^{2}(t)\right)+\sum_{j \in A}\left(x_{j}(T)-\hat{x}_{k}\right)^{2},
$$

here $\hat{x}_{k} \in[0,1]$ is a given desired opinion for player $k$ to which he tries to drive the opinions of all agents in the network selecting his strategy $u_{k}$, and $c_{k}>0$ measures the efforts of this player associated with the selection of $u_{k}$.

The proposed model is a two-person non-cooperative discrete-time linear-quadratic game. The payoff function of player $k \in N$ can be rewritten in a common form for this class of games:

$$
\begin{aligned}
J_{k}\left(u_{1}, u_{2}\right)= & \sum_{t=0}^{T-1}\left(x(t)^{\prime} x(t)+c_{k} u_{k}^{2}(t)-2 \hat{x}_{k} \mathbf{1}^{\prime} x(t)\right)+ \\
& +x(T)^{\prime} x(T)-2 \hat{x}_{k} \mathbf{1}^{\prime} x(T)+|A|(T+1) \hat{x}_{k}^{2}= \\
= & \sum_{t=0}^{T-1}\left(\frac{1}{2} x(t)^{\prime} Q x(t)+\frac{1}{2} R_{k} u_{k}^{2}(t)+q_{k}^{\prime} x(t)\right)+ \\
& +\frac{1}{2} x(T)^{\prime} Q x(T)+q_{k}^{\prime} x(T)+|A|(T+1) \hat{x}_{k}^{2}
\end{aligned}
$$

where 1 denotes a vector of ones of size $|A| ; Q=2 I, I$ is an identity matrix of size $|A|$; $R_{k}=2 c_{k}, q_{k}=-2 \hat{x}_{k} \mathbf{1}$ for $k \in N$.

The above model finds its application in describing the relationship between sellers and consumers in a social network. One can imagine that sellers can promote their products by advertising them in a certain way. The advertising effect as well as the opinions of other members in the social network may drive agent's opinion about the products and thus change his willingness to have them.

3. Solution. In dynamic games, an information structure plays an important role as it is used by players to define their strategies. In this paper, we deal with a feedback information structure and thus a strategy of player $k \in N$ is a mapping that depends on stage $t$ and the current opinion profile $x(t)$, i. e. $u_{k}(t)=\sigma_{k}(t, x(t)) \in[0,1]$, where $\sigma_{k}(\cdot, \cdot):\{0, \ldots, T-1\} \times[0,1]^{|A|} \mapsto[0,1]$. As a solution to this game, we consider a feedback Nash equilibrium which is a pair $\left(\sigma_{1}^{*}, \sigma_{2}^{*}\right)$ such that

$$
J_{1}\left(\sigma_{1}^{*}, \sigma_{2}^{*}\right) \leqslant J_{1}\left(\sigma_{1}, \sigma_{2}^{*}\right) \quad \text { and } \quad J_{2}\left(\sigma_{1}^{*}, \sigma_{2}^{*}\right) \leqslant J_{2}\left(\sigma_{1}^{*}, \sigma_{2}\right)
$$

for all strategies $\sigma_{1}$ and $\sigma_{2}$.

In $[19,20]$, one can find results related to feedback Nash equilibrium for a linearquadratic game of a general structure. Two theorems below characterize a feedback Nash equilibrium for the specific linear-quadratic game under consideration.

Theorem 1. For a discrete-time dynamic game, a pair of strategies $\left(\sigma_{1}^{*}, \sigma_{2}^{*}\right)$ provides a feedback Nash equilibrium if and only if there exist functions $V_{k}(t, \cdot): \mathbb{R}^{|A|} \mapsto \mathbb{R}, t \in \mathcal{T}$, $k \in N$, such that the following relations are satisfied:

$$
V_{k}(t, x)=\min _{u_{k}(t)}\left[\frac{1}{2} x^{\prime} Q x+\frac{1}{2} R_{k} u_{k}^{2}(t)+q_{k}^{\prime} x+V_{k}\left(t+1, W x+b_{k} u_{k}(t)+b_{3-k} \sigma_{3-k}^{*}(t, x)\right)\right] .
$$

Theorem 2. Let matrices $S_{k}(t)$, vectors $p_{k}(t), h_{k}(t)$, and numbers $r_{k}(t), s_{k}(t)$ satisfy the following relations: 


$$
\begin{gathered}
p_{k}(t)\left[R_{k}+b_{k}^{\prime} S_{k}(t+1) b_{k}\right]+p_{3-k}(t) b_{3-k}^{\prime} S_{k}(t+1) b_{k}=W^{\prime} S_{k}(t+1) b_{k}, \\
r_{k}(t)\left[R_{k}+b_{k}^{\prime} S_{k}(t+1) b_{k}\right]+r_{3-k}(t) b_{3-k}^{\prime} S_{k}(t+1) b_{k}=-h_{k}(t+1)^{\prime} b_{k}, \\
S_{k}(t)=Q+R_{k} p_{k}(t) p_{k}(t)^{\prime}+\left[W^{\prime}-\sum_{j \in N} p_{j}(t) b_{j}^{\prime}\right] S_{k}(t+1)\left[W-\sum_{j \in N} b_{j} p_{j}(t)^{\prime}\right], \\
h_{k}(t)=-r_{k}(t) R_{k} p_{k}(t)+q_{k}+\left[W^{\prime}-\sum_{j \in N} p_{j}(t) b_{j}^{\prime}\right] S_{k}(t+1) \sum_{j} r_{j}(t)+ \\
+\left[W^{\prime}-\sum_{j \in N} p_{j}(t) b_{j}^{\prime}\right] h_{k}(t+1), \\
s_{k}(t)=\frac{1}{2} R_{k} r_{k}^{2}(t)+\frac{1}{2} \sum_{j \in N} b_{j}^{\prime} r_{j}(t) \cdot S_{k}(t+1) \sum_{j \in N} b_{j} r_{j}(t)+ \\
+h_{k}(t+1)^{\prime} \sum_{j \in N} b_{j} r_{j}(t)+s_{k}(t+1),
\end{gathered}
$$

for $t=0, \ldots, T-1, k \in N$, with the boundary conditions $S_{k}(T)=Q, h_{k}(T)=q_{k}$, $s_{k}(T)=0$. If $R_{k}+b_{k}^{\prime} S_{k}(t+1) b_{k}>0$ for $k \in N$ and $t=0, \ldots, T-1$, then the feedback Nash equilibrium strategy of player $k$ is given by $\sigma_{k}^{*}=\left\{\sigma_{k}^{*}(t, x(t))=-p_{k}(t)^{\prime} x(t)+r_{k}(t)\right\}$. Player $k$ 's equilibrium payoff in the game is

$$
\begin{gathered}
J_{k}\left(\sigma_{1}^{*}, \sigma_{2}^{*}\right)=V_{k}\left(0, x_{0}\right)+|A|(T+1) \hat{x}_{k}^{2}= \\
=\frac{1}{2} x_{0}^{\prime} S_{k}(0) x_{0}+h_{k}(0)^{\prime} x_{0}+s_{k}(0)+|A|(T+1) \hat{x}_{k}^{2} .
\end{gathered}
$$

4. Numerical simulation. Now we illustrate theoretical results. We suppose that the network consists of set $A$ of ten agents, for which each agent is connected only with three other agents, and set $N=\{1,2\}$ of two players who influence selected agents in the network over twelve periods, so $T=12$. The network is demonstrated in Fig. 1, in which players 1 and 2 are marked by "Pl.1" and "Pl.2", respectively. Consider matrix $W$ and vectors $b_{1}, b_{2}$ of the following form:

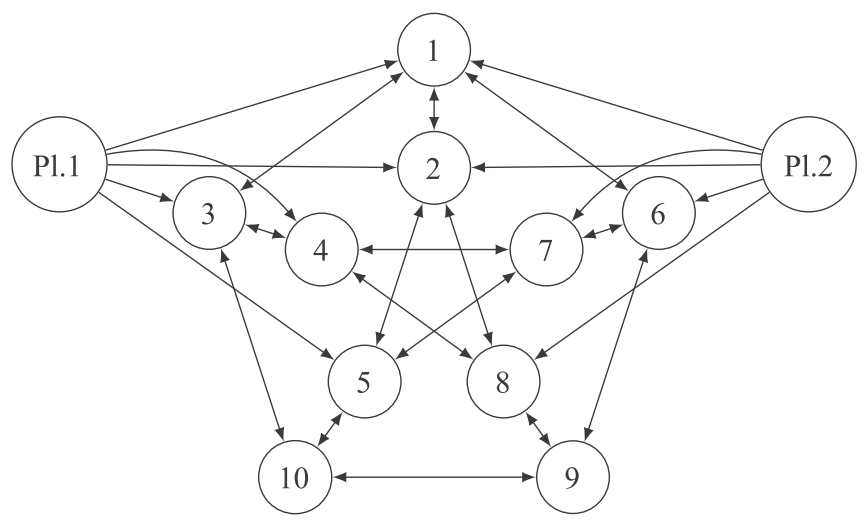

Figure 1. A network with ten agents and two players 


$$
\begin{aligned}
& W=\left(\begin{array}{cccccccccc}
\frac{1-\delta_{1}-\delta_{2}}{4} & \frac{1-\delta_{1}-\delta_{2}}{4} & \frac{1-\delta_{1}-\delta_{2}}{4} & 0 & 0 & \frac{1-\delta_{1}-\delta_{2}}{4} & 0 & 0 & 0 & 0 \\
\frac{1-\delta_{1}-\delta_{2}}{4} & \frac{1-\delta_{1}-\delta_{2}}{4} & 0 & 0 & \frac{1-\delta_{1}-\delta_{2}}{4} & 0 & 0 & \frac{1-\delta_{1}-\delta_{2}}{4} & 0 & 0 \\
\frac{1-\delta_{1}}{4} & 0 & \frac{1-\delta_{1}}{4} & \frac{1-\delta_{1}}{4} & 0 & 0 & 0 & 0 & 0 & \frac{1-\delta_{1}}{4} \\
0 & 0 & \frac{1-\delta_{1}}{4} & \frac{1-\delta_{1}}{4} & 0 & 0 & \frac{1-\delta_{1}}{4} & \frac{1-\delta_{1}}{4} & 0 & 0 \\
0 & \frac{1-\delta_{1}}{4} & 0 & 0 & \frac{1-\delta_{1}}{4} & 0 & \frac{1-\delta_{1}}{4} & 0 & 0 & \frac{1-\delta_{1}}{4} \\
\frac{1-\delta_{2}}{4} & 0 & 0 & 0 & 0 & \frac{1-\delta_{2}}{4} & \frac{1-\delta_{2}}{4} & 0 & \frac{1-\delta_{2}}{4} & 0 \\
0 & 0 & 0 & \frac{1-\delta_{2}}{4} & \frac{1-\delta_{2}}{4} & \frac{1-\delta_{2}}{4} & \frac{1-\delta_{2}}{4} & 0 & 0 & 0 \\
0 & \frac{1-\delta_{2}}{4} & 0 & \frac{1-\delta_{2}}{4} & 0 & 0 & 0 & \frac{1-\delta_{2}}{4} & \frac{1-\delta_{2}}{4} & 0 \\
0 & 0 & 0 & 0 & 0 & \frac{1}{4} & 0 & \frac{1}{4} & \frac{1}{4} & \frac{1}{4} \\
0 & 0 & \frac{1}{4} & 0 & \frac{1}{4} & 0 & 0 & 0 & \frac{1}{4} & \frac{1}{4}
\end{array}\right), \\
& b_{1}=\left(\delta_{1}, \delta_{1}, \delta_{1}, \delta_{1}, \delta_{1}, 0,0,0,0,0\right) \text {, } \\
& b_{2}=\left(\delta_{2}, \delta_{2}, 0,0,0, \delta_{2}, \delta_{2}, \delta_{2}, 0,0\right) \text {, }
\end{aligned}
$$

for some parameters $\delta_{1}, \delta_{2} \in(0,1)$. We consider two scenarios. In the first one players have low influence on agents, i. e. $\delta_{1}=\delta_{1}^{L}, \delta_{2}=\delta_{2}^{L}$. In the second scenario, players' influence is high, i. e. $\delta_{1}=\delta_{1}^{H}, \delta_{2}=\delta_{2}^{H}$. For simulation, let $\delta_{1}^{L}=0.1, \delta_{2}^{L}=0.05, \delta_{1}^{H}=0.4, \delta_{2}^{H}=0.35$. Further, let $c_{1}=0.3, c_{2}=0.4$, the desired opinions for players be $\hat{x}_{1}=0.5, \hat{x}_{2}=0.6$ and the initial agents' opinions be $x_{0}=(1,0.9,0.8,0.7,0.6,0.5,0.4,0.3,0.2,0.1)$.

Table. Feedback Nash equilibrium strategies

\begin{tabular}{|c|c|c|c|c|}
\hline$t$ & $\sigma_{1}^{* L}\left(t, x^{* L}(t)\right)$ & $\sigma_{2}^{* L}\left(t, x^{* L}(t)\right)$ & $\sigma_{1}^{* H}\left(t, x^{* H}(t)\right)$ & $\sigma_{2}^{* H}\left(t, x^{* H}(t)\right)$ \\
\hline 0 & 0.159 & 0.264 & 0.305 & 0.621 \\
1 & 0.295 & 0.315 & 0.373 & 0.665 \\
2 & 0.376 & 0.334 & 0.391 & 0.640 \\
3 & 0.411 & 0.346 & 0.389 & 0.634 \\
4 & 0.427 & 0.351 & 0.387 & 0.630 \\
5 & 0.431 & 0.351 & 0.386 & 0.628 \\
6 & 0.426 & 0.346 & 0.386 & 0.626 \\
7 & 0.412 & 0.334 & 0.386 & 0.623 \\
8 & 0.387 & 0.311 & 0.387 & 0.617 \\
9 & 0.346 & 0.274 & 0.389 & 0.607 \\
10 & 0.282 & 0.215 & 0.391 & 0.580 \\
11 & 0.178 & 0.125 & 0.380 & 0.509 \\
\hline
\end{tabular}

Solving the recurrence relations indicated in the statement of theorem 2 , we note that $R_{1}+\left(b_{1}^{L}\right)^{\prime} S_{1}(t) b_{1}^{L} \in[0.700,0.798]$ and $R_{2}+\left(b_{2}^{L}\right)^{\prime} S_{2}(t) b_{2}^{L} \in[0.825,0.846]$ for all $t=1, \ldots, 12$. Similarly, $R_{1}+\left(b_{1}^{H}\right)^{\prime} S_{1}(t) b_{1}^{H} \in[2.200,2.417]$ and $R_{2}+\left(b_{2}^{H}\right)^{\prime} S_{2}(t) b_{2}^{H} \in[2.025,2.209]$ for all $t=1, \ldots, 12$. Next, we find players' feedback Nash equilibrium strategies (their actions at each stage) which are represented for two scenarios (see table for values and also Figs 2, 3). For both scenarios, agents' opinions are determined as $x^{* L}(t+1)=$ $W x^{* L}(t)+\sum_{k \in N} b_{k} \sigma_{k}^{* L}\left(t, x^{* L}(t)\right)$ and $x^{* H}(t+1)=W x^{* H}(t)+\sum_{k \in N} b_{k} \sigma_{k}^{* H}\left(t, x^{* H}(t)\right)$ for $t=0, \ldots, T-1$ with $x^{* L}(0)=x^{* H}(0)=x_{0}$. The equilibrium opinion dynamics is demonstrated in Figs 4, 5 with the following terminal agents' opinions: 


$$
\begin{aligned}
& x^{* L}(12)=(0.379,0.379,0.402,0.402,0.403,0.414,0.412,0.413,0.439,0.437), \\
& x^{* H}(12)=(0.452,0.452,0.427,0.443,0.441,0.516,0.499,0.501,0.517,0.468)
\end{aligned}
$$

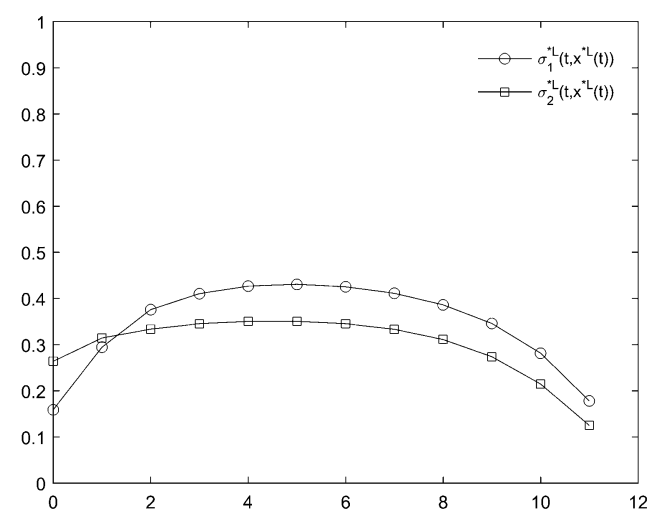

Figure 2. Feedback Nash equilibrium strategies $\sigma_{1}^{* L}\left(t, x^{* L}(t)\right)$ and $\sigma_{2}^{* L}\left(t, x^{* L}(t)\right)$

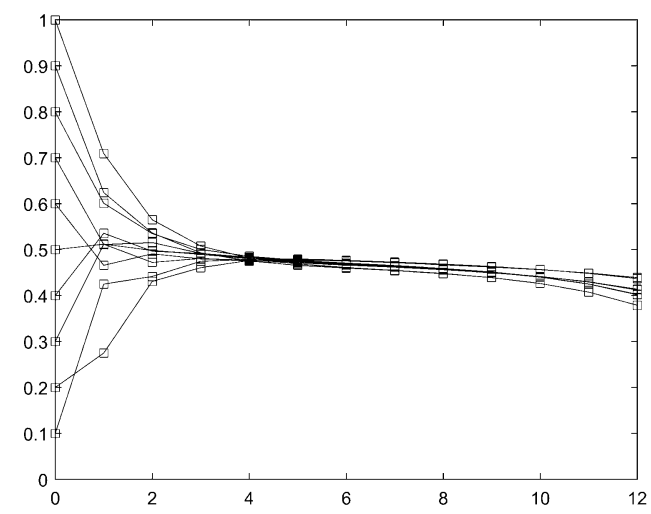

Figure 4. Equilibrium opinions $x_{i}^{* L}(t)$, $i \in A, t=0, \ldots, 12$

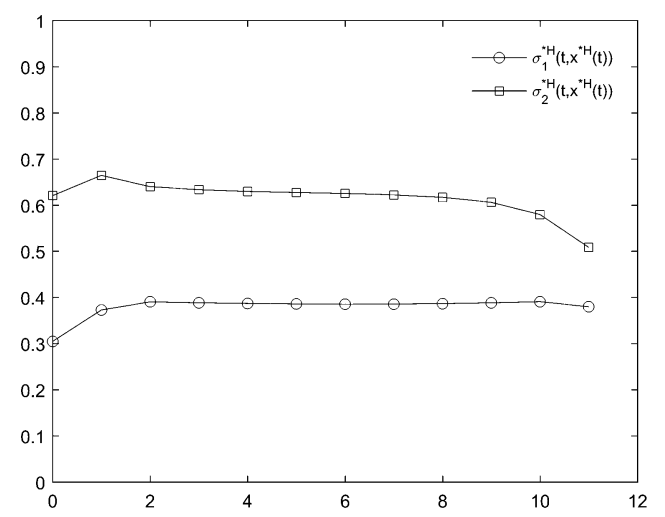

Figure 3. Feedback Nash equilibrium strategies $\sigma_{1}^{* H}\left(t, x^{* H}(t)\right)$ and $\sigma_{2}^{* H}\left(t, x^{* H}(t)\right)$

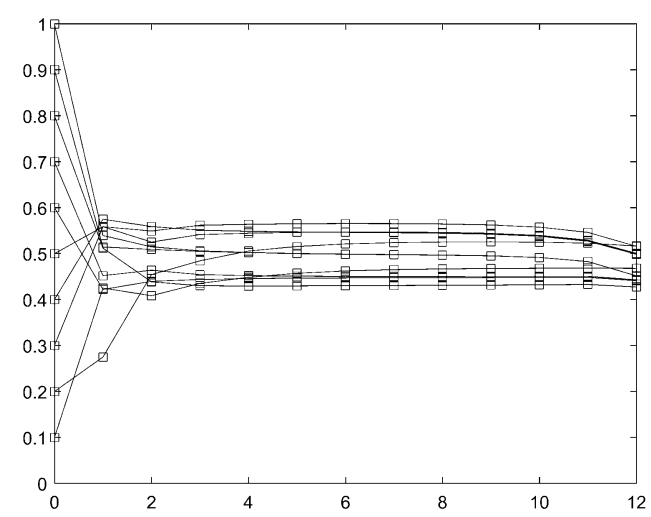

Figure 5. Equilibrium opinions $x_{i}^{* H}(t)$, $i \in A, t=0, \ldots, 12$

Players' payoffs under the two feedback Nash equilibria are

$$
\begin{gathered}
J_{1}\left(\sigma_{1}^{* L}, \sigma_{2}^{* L}\right)=1.711, \quad J_{2}\left(\sigma_{1}^{* L}, \sigma_{2}^{* L}\right)=3.753, \\
J_{1}\left(\sigma_{1}^{* H}, \sigma_{2}^{* H}\right)=1.671, \quad J_{2}\left(\sigma_{1}^{* H}, \sigma_{2}^{* H}\right)=4.387 .
\end{gathered}
$$

5. Conclusion. In the paper, we proposed a two-person discrete-time game in a social network. Assuming that players behave non-cooperatively under feedback information structure, we used the concept of feedback Nash equilibrium as a solution to the game. To perform numerical simulation, we considered a social network with the agents of three 
types: a) agents influenced by both players; b) agents influenced only by one player; c) agents not influenced by players directly. For two scenarios of players' influence, we presented equilibrium strategies and agents' equilibrium opinions.

Acknowledgments. The authors thank two anonymous referees for their comments that have helped in the improvement of the paper.

\section{References}

1. DeGroot M. H. Reaching a Consensus. Journal of the American Statistical Association, 1974, vol. 69 , no. 345 , pp. $118-121$.

2. Friedkin N. E., Johnsen E. C. Social influence and opinions. Journal of Mathematical Sociology, 1990, vol. 15, no. 3-4, pp. 193-206.

3. Friedkin N. E., Johnsen E. C. Social influence networks and opinion change. Advances in Group Processes, 1999, vol. 16, pp. 1-29.

4. Bauso D., Cannon M. Consensus in opinion dynamics as a repeated game. Automatica, 2018, vol. 90, pp. 204-211.

5. Bindel D., Kleinberg J., Oren S. How bad is forming your own opinion? Games and Economic Behavior, 2015, vol. 92, pp. 248-265.

6. Acemoglu D., Ozdaglar A. Opinion dynamics and learning in social networks. Dynamic Games and Applications, 2011, vol. 1, no. 1, pp. 3-49.

7. Buechel B., Hellmann T., Klößner S. Opinion dynamics and wisdom under conformity. Journal of Economic Dynamics and Control, 2015, vol. 52, pp. 240-257.

8. Dandekar P., Goel A., Lee D. T. Biased assimilation, homophily, and the dynamics of polarization. Proceedings of the National Academy of Sciences, 2013, vol. 110, no. 15, pp. 5791-5796.

9. Hegselmann R., Krause U. Opinion dynamics and bounded confidence models, analysis, and simulation. Journal of Artificial Societies and Social Simulation, 2002, vol. 5, no. 3, pp. 615-645.

10. Ghaderi J., Srikant R. Opinion dynamics in social networks with stubborn agents: Equilibrium and convergence rate. Automatica, 2014, vol. 50, no. 12, pp. 3209-3215.

11. Golub B., Jackson M. O. Naive learning in social networks and the wisdom of crowds. American Economic Journal: Microeconomics, 2010, vol. 2, no. 1, pp. 112-49.

12. Bure V., Parilina E., Sedakov A. Consensus in social networks with heterogeneous agents and two centers of influence. Stability and Control Processes in memory of V. I. Zubov (SCP), 2015 Intern. Conference, 2015, pp. 233-236.

13. Bure V., Parilina E., Sedakov A. Consensus in a social network with two principals. Automation and Remote Control, 2017, vol. 78, no. 8, pp. 1489-1499.

14. Barabanov I. N., Korgin N. A., Novikov D. A., Chkhartishvili A. G. Dynamic models of informational control in social networks. Automation and Remote Control, 2010, vol. 71, no. 11, pp. 24172426 .

15. Gubanov D. A., Novikov D. A., Chkhartishvili A. G. Informational influence and informational control models in social networks. Automation and Remote Control, 2011, vol. 72, no. 7, pp. 1557-1597.

16. Etesami S. R., Başar T. Game-theoretic analysis of the Hegselmann-Krause model for opinion dynamics in finite dimensions. IEEE Transactions on Automatic Control, 2015, vol. 60, no 7, pp. 18861897.

17. Krawczyk J. B., Tidball M. A discrete-time dynamic game of seasonal water allocation. Journal of Optimization Theory and Applications, 2006, vol. 128, no. 2, pp. 411-429.

18. Niazi M. U. B., Özgüler A. B., Yıldız A. Consensus as a Nash equilibrium of a dynamic game. 12th Intern. Conference on Signal-Image Technology \& Internet-Based Systems, 2016, pp. 365-372.

19. Başar T., Olsder G. J. Dynamic noncooperative game theory. 2nd ed. New York, Academic Press, $1999,511 \mathrm{p}$.

20. Haurie A., Krawczyk J., Zaccour G. Games and dynamic games. Singapore, World Scientific Press, 2012, 488 p.

Received: September 11, 2018.

Accepted: December 18, 2018.

Author's information:

Artem A. Sedakov - PhD in Physics and Mathematics; a.sedakov@spbu.ru

Mengke Zhen - Student; mengkezhen@163.com 


\section{Игра динамики мнений в социальной сети с двумя центрами влияния *}

A. A. Седаков ${ }^{1,2,3}$, М. Чжэнъ ${ }^{1}$

1 Санкт-Петербургский государственный университет, Российская Федерация, 199034, Санкт-Петербург, Университетская наб., 7-9

2 Школа математики и статистики, Университет Циндао, Китайская Народная Республика, 266071, Циндао, Нинся Роад, 308

3 Институт прикладной математики Шаньдуна, Китайская Народная Республика, 266071, Циндао, Нинся Роад, 308

Для цитирования: Sedakov A. A., Zhen M. Opinion dynamics game in a social network with two influence nodes // Вестник Санкт-Петербургского университета. Прикладная математика. Информатика. Процессы управления. 2019. Т. 15. Вып. 1. С. 118-125. https://doi.org/ 10.21638/11702/spbu10.2019.109 (In English)

В статье исследована конфликтно-управляемая модель динамики мнений в социальной сети с двумя центрами влияния. Центры посредством выбора уровней влияния на остальных участников сети преследуют определенные интересы. При рассмотрении этой модели как некооперативной игры двух лиц и выборе в качестве ее решения равновесия по Нэшу найдены равновесные уровни влияния для каждого из центров.

Ключевые слова: социальная сеть, влияние, динамика мнений, равновесие.

Контактная информация:

Седаков Артем Александрович - канд. физ.-мат. наук; a.sedakov@spbu.ru

Чэсэнъ Мэнкэ - студент; mengkezhen@163.com

* Работа выполнена при финансовой поддержке Российского фонда фундаментальных исследований (грант № 17-51-53030) и провинции Шаньдун "Double-Hundred Talent Plan" (грант № WST2017009).

Вестник СПбГУ. Прикладная математика. Информатика... 2019. Т. 15. Вып. 1 